\title{
Security Experts Innovation and Investment Front for IT-Entrepreneurship in Pakistan
}

\author{
Muhammad Qasim Yasin', Zhiyong Feng ${ }^{2}$, Ahmed Mateen ${ }^{3}$, Salman Afsar ${ }^{4}$, Abdul Rehman ${ }^{5,}$ \\ Asim Saif ${ }^{6}$ \\ ${ }^{1,2}$ College of Intelligence and Computing, Tianjin University, Tianjin Key Laboratory of Cognitive Computing \\ and Application, Tianjin, China. \\ ${ }^{3,4}$ Computer Science Department, University of Agriculture Faisalabad, Pakistan. \\ Zip Code:38000,Email:ahmedbuttar@uaf.edu.pk \\ ${ }^{5,6}$ College of Intelligence and Computing, Tianjin University, Tianjin Key Laboratory of Advance Networking, \\ Tianjin, China
}

\begin{abstract}
Innovation in the field of entrepreneurship is the subject of this study. It lacks in Pakistanas compared to other regions like India, Malaysia and China. In this explanatory as well as exploratory study, the issue has been highlighted in it's true spirit and important direction for policy makers has been identified. IT is very important as a technology and as a growing community as well. management processes in IT are broad and complex and a lot of attention is usually required in terms of capital, human variables and technology. Moreover, all projects have specific and important success factor which need to be taken into account for increasing chances of implementing the projects successfully. State of the art intelligent support system as well as It staff are very crucial in achieving such success and making important decisions. We have explored this issue in our paper and have elaborated important points for observing the implemented strength as well as its enhancement.
\end{abstract}

Key words : Big IT-Players, IT- Entrepreneurial-Culture, IT- Incentives, Security and Defense Forces.

\section{INTRODUCTION}

Entrepreneurship is the process of building a new value by utilizing appropriate time and effort. This process includes financial, professional and social compatibilities for achieving more financial satisfaction and independence in existing recourses. IT-based trading is a powerful innovative way to create more wealth. The product or service itself needs not to be new or unique, but entrepreneurs must sell the extended value by providing or distributing the skills and resources wherever required. The term "entrepreneur" refers to people who have a potential for those things, which generally is considered risk in the businesses; they are daring contractors, knowing the art of gaining and losing. IT-related business shapes the future of customers and make a bound to inspire a new narrative with contemporary business models and methods of customer engagement that will transform the way the economy creates value. ICTs provide an opportunity for nations to address the digital divide and reduce poverty while registering economic growth. Child labor is done due to poverty and simultaneously it also reduces the literacy rate [1], [2]. As per-capita income levels increase, without hesitation, parents prefer to educate their children instead of them doing manual labor. This situation will boost IT education and professional studies in Pakistan, which has seen the emergence of a vibrant ICT sector that significantly contributes towards national gross domestic product (GDP). IT infrastructure can make organizations and industries to sell their goods and receive the maximum benefits from market. In this respect, all procurement and production will be done with a state-of-the-art approach under the umbrella of automated IT-based infrastructure. This will result in the expansions of the customer base for the new innovative IT services and it will truly turn into the practicability of investment for the innovation [3]. This will make firms not to face the problem of the absorbing of the various tariff costs and the trade barriers. Restrictions on foreign investments can possibly be the best deal with IT entrepreneurship. To make a boost up to the economy, new capital entering is possible with IT related flexible policies. Many factors like banking, marketing, advertise etc. will lead to investment so the growing businesses will produce IT related jobs in this regards people income and standards of the living of will defiantly increase. ultimately will rise the productivity cycle of industries [4].

If we compare Pakistan with its sister country India, one news cutting shows the whole picture " 1.3 million students sit in for Indian Institute of Technology (IITs) admission tests. This does not factor in the national and regional institutes which further add to the engineering talent base. Pakistan needs far more engineering institutes than it currently has. Following the swelling of the engineering talent pool, India has also seen a large uptake in Venture Capital (VC), driven largely by healthy returns in technology. Indian alumni 
working overseas fuel a lot of this and having established themselves in enviable executive positions - the CEOs of Google, Microsoft and Adobe are all of Indian origin. Bollywood has also jumped on the bandwagon with most actors going beyond just endorsements and actually taking partnerships in tech startups" [13].

\subsection{Critical Success Path}

The first order, these IT management factors set the critical success path [5]:

1. Project Management Methodology

2. Skilled Project Team

3. Purified and optimized approach

4. Successfully Implementation

5. Properly Documented

These three factors in the context of the IT management plan are engaged in the implementation phase of the software development life cycle. Strategic issues are important tactical issues and have become increasingly important from start to end. IT managers/ leaders must consider following strategy and tactical issues:

- Understanding IT management services: A good business relationship is based on the corporate culture; therefore, IT management should be given authority which will be deemed to create new administrative changes which, so ever, are desirable for more "automated system elements" [6].

IT Sponsorship and Management Lifecycle: The role of a mentor is there to manage IT managers, in addition to constantly remind of the required level of expertise. It is very important that the IT team understands the objectives and values of the business and it is very important as well.

- Current and active innovation: in IT Management participation is always desired to be reflected in Management capabilities [7].

- Adaptability Organizations: Adaptability refers to the firm and the firm's ability to rapidly and effectively respond to market changes, or it is much better to say, global e-market changes. Two key factors involved in this adaptation have been proven superior; i) informal IT management, and ii) a simple but rigid IT structure [8].

- Selection Criteria of Project: Four criteria are generally used, which include: i) IT managers must be result-oriented, ii) have good technical skills, iii) be committed to the organization and iv) have in-depth knowledge of the company's value.

- Leadership: Typically, IT managers have a big responsibility; however, the real authorities are the firm's leaders and managers but they have limited IT responsibility. This creates gap in nearly every organization. In Pakistan, since the independence of the country, most company owners are cabalists or dynasties of various forms and belong to the upper class. In this context, maintaining IT-style leadership for IT managers with adjustment decision control is very important [9].

\section{MATRIALS AND METHODS}

The key factors involved in the planning and control cycle consists of a detailed information and transaction plan, which data managers should continue to monitor, and be ever ready to adapt and restructure if it does not work, before it is too late. Experience shows that the data managers and leadership style of the human factor is one of the key factors for a successful computerization implementation. This consists of a set of people skills, experience and qualifications management.

There are six key factors which are explored in this research for establishing good enterprise-level utilization of IT experts' performance on the innovation and investment front:

\section{A. IT experts in relation with Security and Defense Forces (SDF):}

- IT experts, both men and women, serve as a team with SDF.

- IT experts play technical roles; gain a significant form of training for cyber-tech, cyber-security, as well as other activities which also provide a strong base for success in terms of IT-service.

- Many cyber-experts are heads of various social security organizations.

- IT experts start their own businesses using these skills they have obtained for making strong IT security bases.

- Domestic development of automation and software should make the industry to linked with modern world Technologies easily to achieve their goals.

The results regarding this are shown in Figure 1.

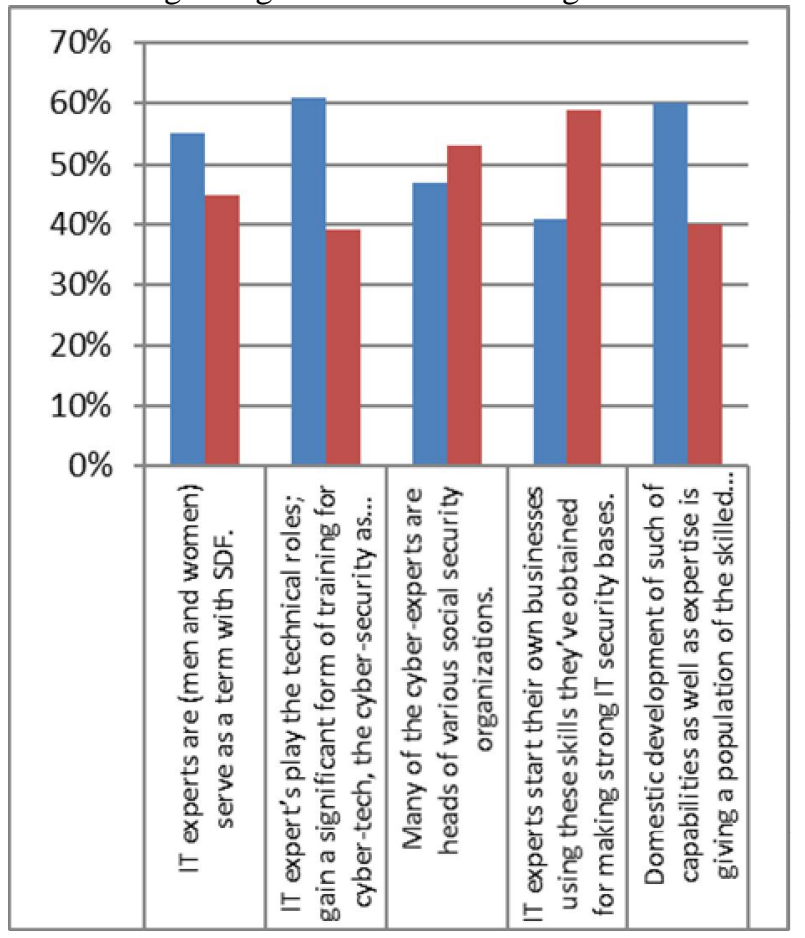

Figure 1: IT experts in relation with Security and Defense Forces (SDF) 


\section{B.Strong Spirit of Entrepreneurialism:}

- The existence of several R\&D Centers and Business Accelerators in the country.

- IT experts are a strong spirit of entrepreneurialism.

- Do young people have vision of preliminary own IT firm.

- Does companies and government interested to help to assure a culture of creativity in society. Does a community approach exit over it?

The results are shown in Figure 2.

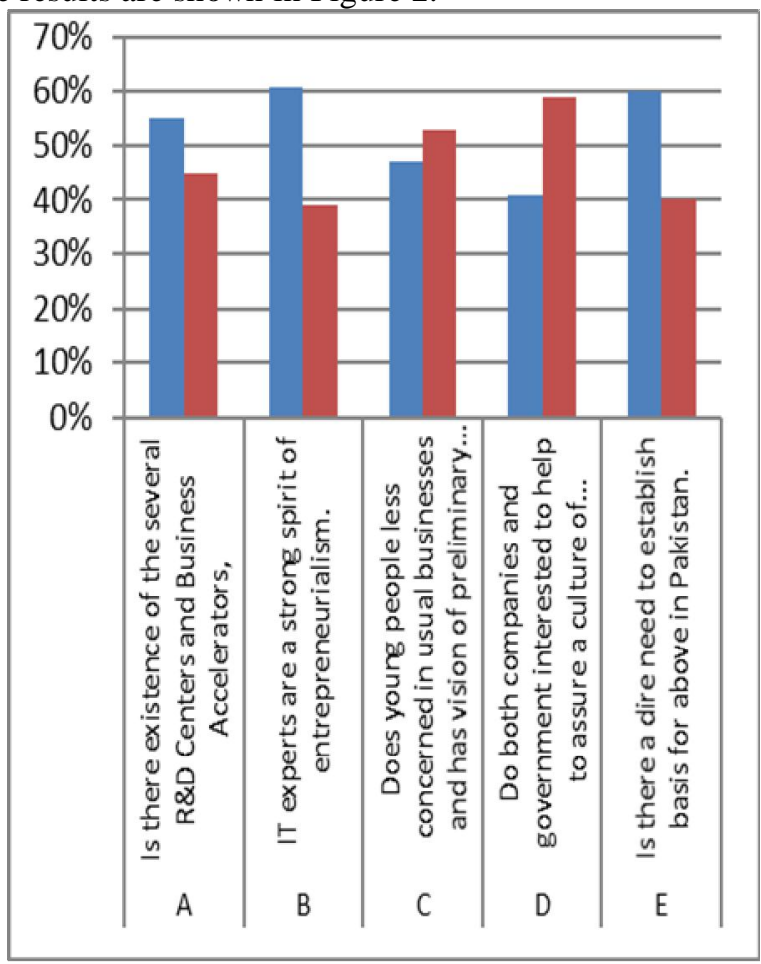

Figure 2: Strong Spirit of Entrepreneurialism

\section{Assessment of Presence and Absence of 'Big IT-Players' (BITP):}

- Are big giants like Google, IBM, Samsung, Apple, Amazon, Cisco, Tweeter, Facebook, LinkedIn, Microsoft, Intel etc. directly involved as technology players in Pakistan?

- Most of the companies are investing in R\&D as well as talent hunt for better opportunities.

- Government should attract the other IT-companies and these will join our local market.

- Does Government has already policies to bring these in Pakistan

- Do the Local software firms are capable to attract them will unmatched skills and ideas?

The results are shown in Figure 3.

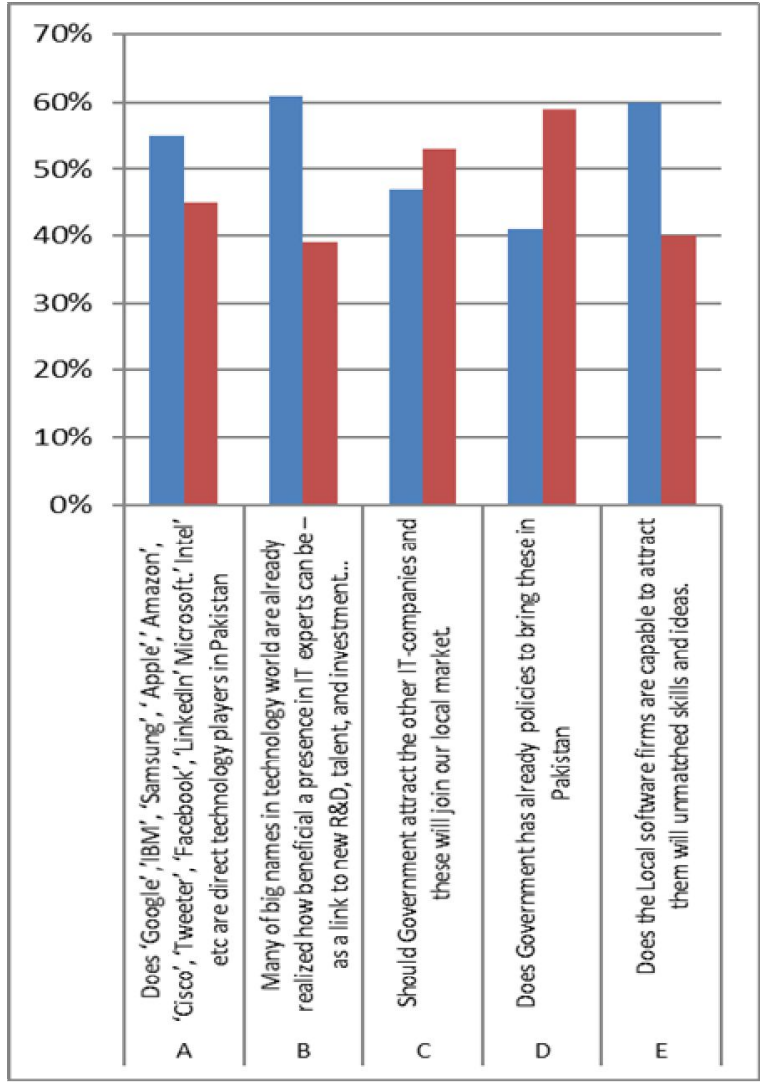

Figure 3: Assessment of the Presence and Absence of 'Big IT-Players'

\section{D.Attractiveness for Tech. Investors:}

- A lot of opportunities are available for IT Investment.

- Medical and engineering fields are open as well for technology experts.

The results are shown in Figure 4.

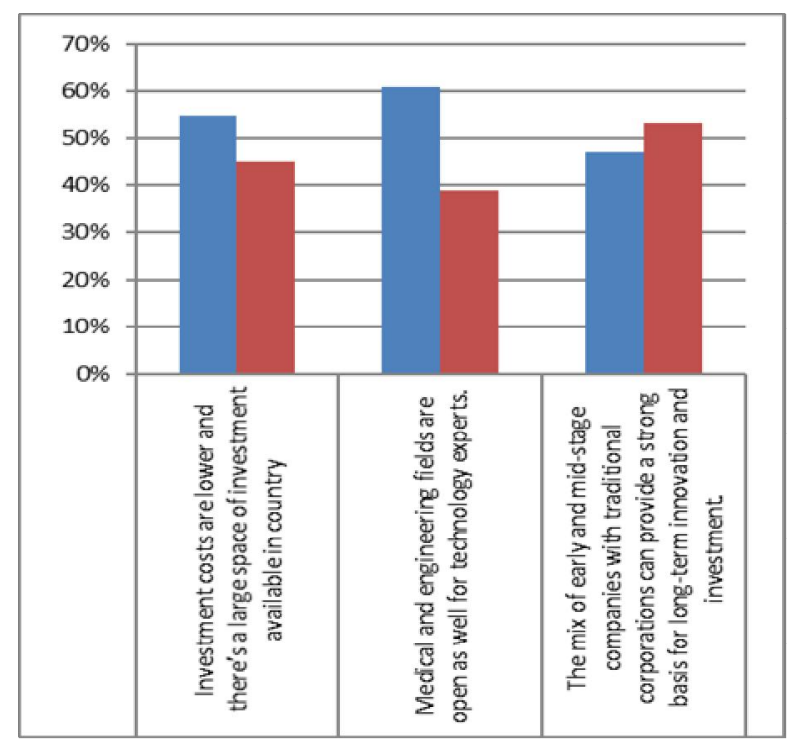

Figure 4: Attractiveness for Tech Investors 


\section{E.IT-Incentives (ITI):}

- A number of large corporations are interested to invest in the R\&D center domain.

- Government is also willing to provide R\&D grants for IT experts.

- Additional grants required for R\&D projects conducted in certain development areas.

- Encouraging joint ventures and entrepreneurship.

The results are shown in Figure 5.

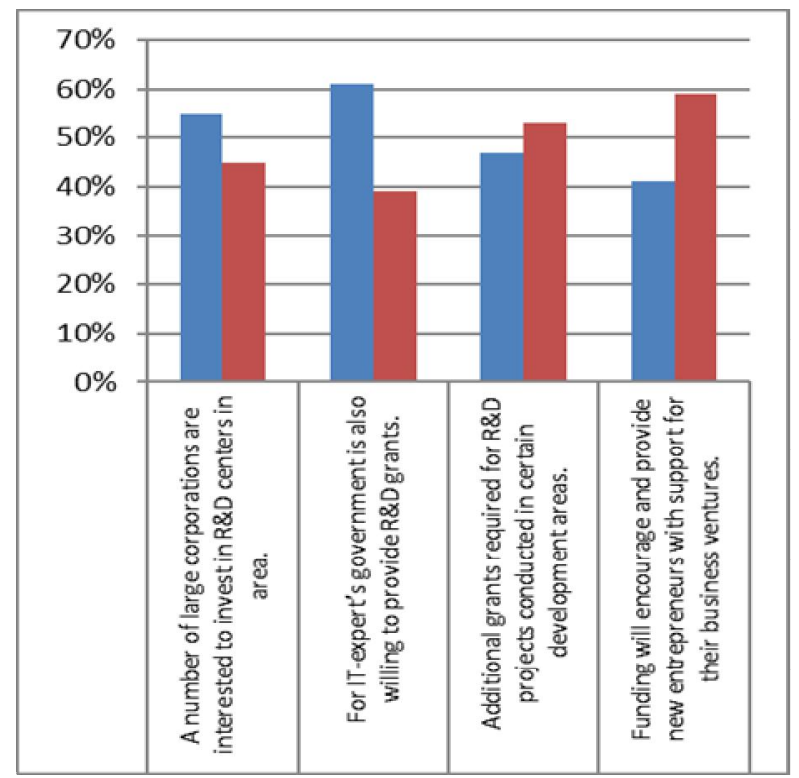

Figure 5: IT-Incentives

\section{F. Advanced Structure for Innovation:}

- With the rise of IT-related services and new technology trends will developed innovation hub and country needs to develop a strong advisory services support.

- IT-based accelerator development programs are the real need of the day.

- Firms like legal, accounting, advisory, incubators, accelerators for corporate venture capital should be enabled for more investment opportunities.

- More opportunities are required for R\&D as new ideas and innovations, so more people will be benefit by the intellectuals and advisors [10].

The results are shown in Figure 6.

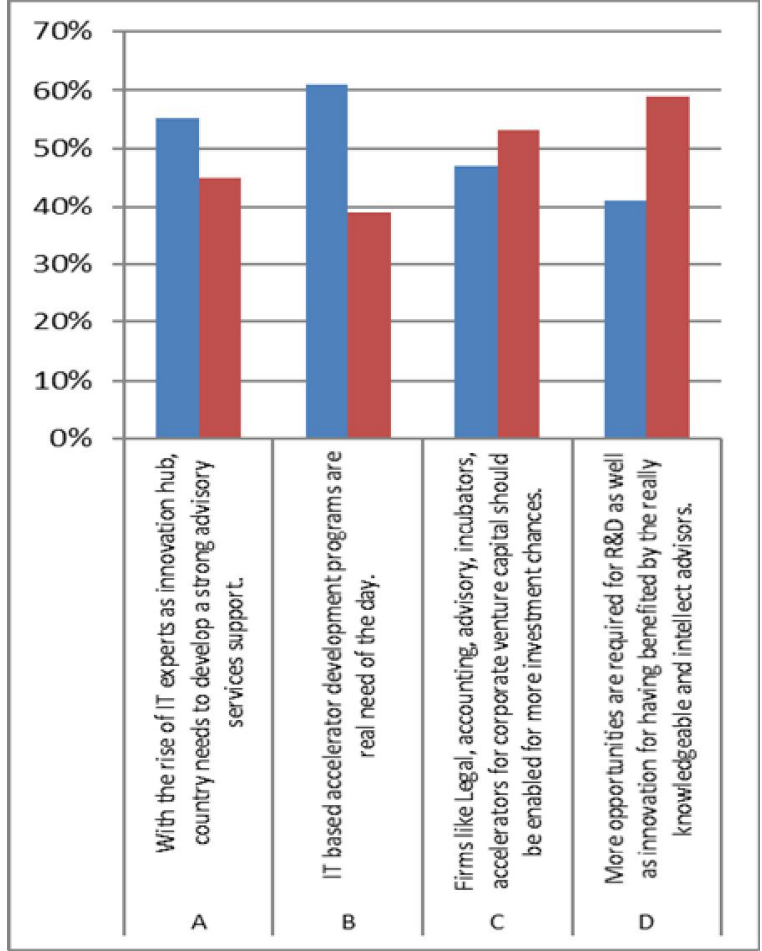

Figure 6: Advanced Structure for Innovation

\section{RESULTS}

The success of software development is based on the utilization of the correct project management approach. Figure 7 shows overview of the investment insight in Pakistan [14]. Figure 8 shows that total domestic earnings are much less than total earnings. The local market needs to follow the recommendations of IT entrepreneurship in order to fill the gap .

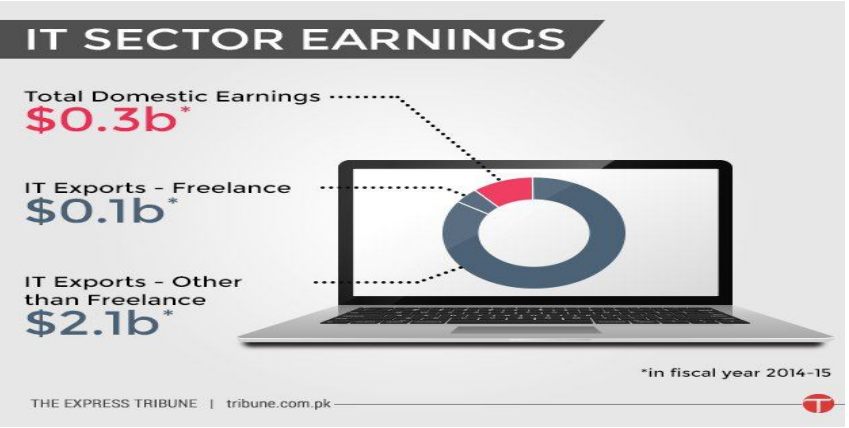

Figure 7: IT Investment in Pakistan [13] 


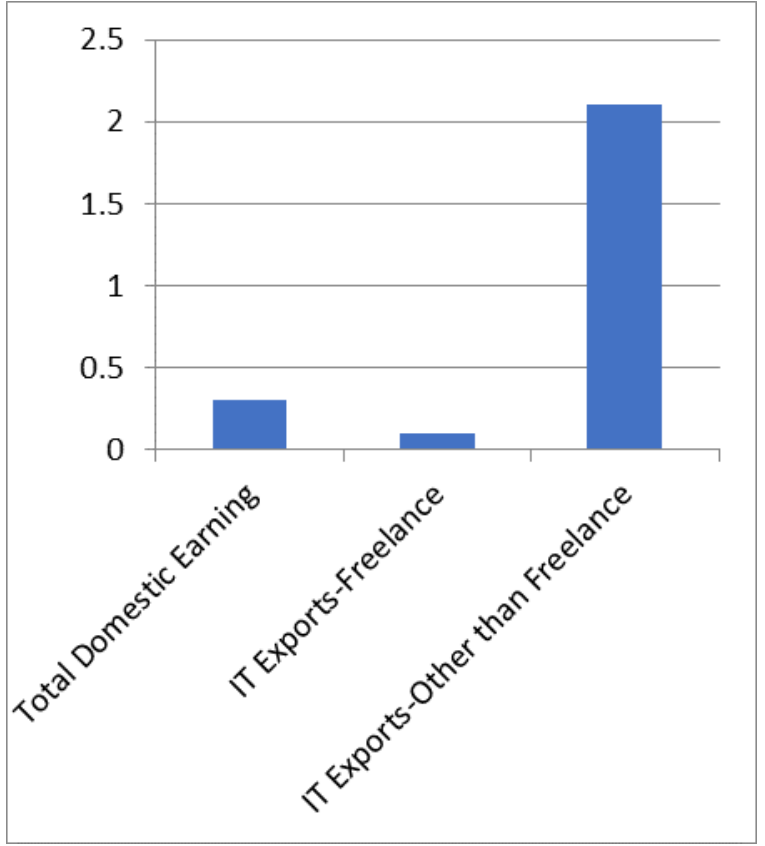

Figure 8: IT investment in Pakistan [14]

The foundation of the enterprise possible working is as below:

\section{A. Policy and Legal Framework}

Development of IT-based services and infrastructure should be one of the main agendas of government. An e-Government policy and legal framework should be established and its adoption enforced in all government organizations [15].

\section{B. Financial Barriers}

By the adaptation of computerization in all public-sector organizations all financial matters are easily auditable. Every person and department working should be easily watchable which will control illegal use of power and resources and save lot of money drain [16].

\section{Highly Qualified Workforce}

IT has a very highly qualified workforce. Nowadays, people have good IT literacy rates and above average years of schooling; this is especially so in urban communities, while less so in the rural community [17], [18].

\section{Mandatory Computer Education}

Rationalize the education system in with computer education is mandatory agenda which will enhance the abilities of children's in term of knowledge discovery, improved their learning process, usage, linkage with industry which will ultimately helpful for easy job placement [19], [20].

\section{E. Recognition of IT to the Public Offices}

Capacity building workshops should be arranged in all government sectors to increase educate the people which will increase their motivation level and sprit of working to adopt the IT based services and platforms [21].

\section{F. Informal, non-hierarchical IT-culture Development}

IT professionals are usually informal and to the point etc., and this attitude might be compared with other professionals. Computer professionals mostly will not hesitate in producing facts, if they think them suitable for decision making. This might be considered insecure in many situations, but IT people are dependent on software with what they think and they work. This turns it simple to question the authorities sometimes [22].

\section{G. Competition between IT people}

There is plenty of healthy competition between IT people. Firms are acquiring software to go online. Some firms have capital and they require IT people to be Amazon partners etc. This growing competition is necessary for the growth is IT in Pakistan [13].

\section{H. Security Measures}

Proper security measures should be followed and include password protected computers, user roles with policies, antivirus software and a firewall installation plan, which should not be compromised in the public private network environment for secure data processing [11].

\section{Public incentives}

Many organizations view incentives as an important tool for improving performance. Rewarding high performers, and ignoring or punishing low performers, correlates strongly to greater overall corporate performance. Therefore, the public incentives in form of new recognition can lead the IT to right path in Pakistan.

\section{J. Community Services}

Establish a coordination wing in all departments which will facilitate the general public to help and motivate them to use IT services like online income tax return, utility payments, online banking so people can addicted and easily used new developed IT solutions [12].

\section{CONCLUSION}

The purpose of the paper is to study the role of entrepreneurs to make IT intensive firms and organizations. The study has focused on the software sector to integrate it with local markets (which is currently lacking regarding IT tools) and to realize the strength of IT in organizations to achieve their goals and make future plan with smoothly and effectively.

Currently, many software centers have expanded their research to the entire sector, with the exception of global companies.

The issues emphasized in this study are as follows:

(i)How IT-entrepreneurs improves can improve the relevant technology skills, thereby giving rise to new companies and fostering the succeeding economical and modern activities.

(ii) What are the characteristics of those IT tactics and how they can be used in building a competitive IT sector? 
Muhammad Qasim Yasin et al., International Journal of Emerging Trends in Engineering Research, 8(9), September 2020,6457 - 6463

(iii) Having capacity to solve the issues within no time constraints.

The goal of this study was to explore the possible contributions made by IT entrepreneurs to companies, in terms of the origin, shape, characteristics of company's strategy, as well as those made to society.

This study focused on a sample of about 150 people from renowned IT firms. Moreover, the articles of newspapers and social media have also been made part of the study. there are many macro and micro factors involved in the study. Six macro factors were taken into the consideration and we tried to relate them with some of very important micro factors. The study is valid for the countries of Middle East, Africa, developing countries of Asia, India and some of other states as well. A questionnaire was used to collect feedback from potential respondents. The questionnaire was divided into six parts. The first section focused on determining the current situation of IT firms and the need to have been IT tactics and technologies in defense and security institutes. The second part assessed the level of the spirit of entrepreneurship, and the third part was related to the role of key players in IT. The last three parts assessed IT skills, incentive and It culture. The study was carried out with the consideration that IT management processes are complex and broad, and generally require extensive attention to the collective aspect of human variables, capital and technologies. In addition, projects tend to have a special set of critical success factors which can be processed and given attention to improve the chances of successful implementation. The critical factors include the clarity of specific goals as well as the direction of management. This is possible by seeking willingness and possible determinations of the leadership for providing critical resources and authority of required power for project success. These incentives include [14].

- Provision of low-rent Software Technology Parks (STPs), with fiber-optic connectivity to libraries and conference rooms.

- Allowing 100\% ownership of equity for investing foreign IT companies.

- Income tax exemption on IT-export revenues until June 2019.

- Allowing $100 \%$ repatriation of profits for foreign IT companies.

- A seven-year tax holiday for venture capital funds.

- Minimum rate of $30 \%$ depreciation on computer equipment.

- The State Bank of Pakistan (SBP) has allowed banks to open Internet Merchant Accounts.

- Availability of instant and reliable high-speed connectivity.

- Over $85 \%$ of telecommunication infrastructure is on fiber-optic cables.

- Internet access is available in over 2000 cities/ towns across Pakistan.

- Reduction in cost of 2 Mbps connection to US\$ 500 from $\$ 700$ per month.
- Call centers can avail redundant backup connectivity through the Pakistan Telecommunication Company Limited (PTCL).

The paper suggests that industries should focus these points during their project execution which includes the good consultation and acceptance of the clients, strict monitoring of the feedbacks. herewith the communications and abilities to troubleshoot the remote problems which will leads as a key role to IT innovations. The government should support IT industries in the form of better incentives and promote public private partnerships. As a result, local and foreign consortiums will develop a strong infrastructural backbone in the IT industry. These initiative in educational institutes will produce IT manpower which will also contribute their efforts to evolved in demanding and growing industry.

\section{REFERENCES}

[1] S. Aparicio, D. Urbano, and D. Gómez. The role of innovative entrepreneurship within Colombian business cycle scenarios: A system dynamics approach, Futures, Vol. 81, pp. 130-147, 2016.

[2] R. Brown, and C. Mason. Inside the high-tech black box: A critique of technology entrepreneurship policy, Technovation, Vol. 34, no. 12, pp. 773-784, 2014.

[3] Dangolani, and S. Khajeh. The Effect of Information Technology in the Entrepreneurship (A Case Study in Golestan Province IRAN), Procedia-Soc. Behav. Sci., Vol. 30, pp. 10-12, 2011.

[4] Harms, and Rainer, Self-regulated learning, team learning and project performance in entrepreneurship education: Learning in a lean startup environment, Technolog. Forecast. Soc. Change, Vol. 100, pp. 21-28, 2015.

[5] E. Muralidharan, and S. Pathak. Informal Institutions and International Entrepreneurship, International Business Review, Vol. 26, no. 2, pp. 288-302. 2017.

[6] A. Navarro-García. Drivers of export entrepreneurship, International Business Review, Vol. 25, no. 1, pp. 244-254, 2016.

[7] J. Porfírio, T. António, T. Carrilho, and L. S. Mónico. Entrepreneurship in different contexts in cultural and creative industries, Journal of Business Review, Vol. 69, no. 11, pp. 5117-5123, 2016.

[8] A. Rauch, and E. James. Dynastic entrepreneurship, entry, and non-compete enforcement, European Economic Review, Vol. 86, pp. 188-201, 2016.

[9] S. Staniewski, and W. Marcin. The contribution of business experience and knowledge to successful entrepreneurship, Journal of Business Review, Vol. 69, no. 11, pp. 5147-5152, 2016.

[10] H. Sulistyo, and Siyamtinah. Innovation capability of SMEs through entrepreneurship, marketing capability, relational capital and empowerment, Asia Pacific Management Review, Vol. 21 no. 4, pp. 196-203, 2016. 
[11] W. Chih-Wen, Global entrepreneurship and innovation in management: Comparing MRA/SEM versus fuzzy-set QCA theory creation, data analysis, and findings, Journal of Business Research, Vol. 69, no. 6, 2061-2066, 2016.

[12] V. K. L. Srivastava, N. C. S. Reddy and A. Shrivastava. An efficient Software Source Code Metrics for Implementing for Software quality analysis, International Journal of Emerging Trends in Engineering Research, Vol. 7, no. 9, pp. 216-222, 2019.

[13] B. G. Sudarsono, F. H. Hartono, D. Y. Bernanda and J. F. Andry. Adopting SCRUM Framework in a Software Development of Payroll Information System, International Journal of Advanced Trends in Computer Science and Engineering, Vol. 9, no. 3, pp. 26045-2611, 2020.

[14] M. Yaseen, A. Mustapha, M. A. Salamat and N. Ibrahim. Prioritization of Software Functional Requirements: A Novel Approach using AHP and Spanning Tree, International Journal of Advanced Trends in Computer Science and Engineering, Vol. 9, no. 1, pp. 51-56, 2020.

[15] R. Vallon, B. J. D.S. Estacio, R. Prikladnicki and T. Grechenig. Systematic Literature Review on Agile Practices in Global Software Development, Information and Software Technology, Vol. 96, pp. 161-180, 2017.

[16] S. Mahmood, M. Alshayeb, M. R. Riaz, K. Faisal, N. Cerpa, S. U. Khan and I. Richardson. Key factors that influence task allocation in global software development, Information and Software Technology, Vol. 91, pp. 102-122, 2017.

[17] M. Niazi, S. Mahmood, M. Alshayeb. Challenges of project management in global software development: A client-vendor analysis, Information and Software Technology, Vol. 80, pp. 1-19, 2016.

[18] M. Zahedi, and M. A. Babar. Why does site visit matter in global software development: A knowledge-based perspective, Information Software Technology, Vol. 80, pp. 36-56, 2016.

[19] C. Manteli, B. V. D. Hooff, and H. V. Vliet. The effect of governance on global software development: An empirical research in transactive memory systems, Information Software Technology, Vol. 56, no.10, pp. 1309-1321, 2014.

[20] J. M. Verner, O. P. Brereton, B. A. Kitchenham, M. Turner and M. Niazi. Risks and risk mitigation in global software development: A tertiary study, Information Software Technology. Vol. 56, no. 1, pp. 54-78, 2014.

[21] S. Nidhra, M. Yanamadala, W. Afzal and T. Richard. Knowledge transfer challenges and mitigation strategies in global software development-A systematic literature review and industrial validation, International Journal of Information Management, Vol. 33, no. 2, pp. 333-355, 2013.

[22] L. Layman, L. Williams, D. Damian and H. Bures. Essential communication practices for Extreme
Programming in a global software development team, Information Software Technology, Vol. 48, no. 9, pp. 781-794, 2006. 